\title{
The Impact of the E-book on Levels of Bloom's Pyramid at ECT Students in Light of the Internal and External Motivation to Learn Mathematics and Statistics
}

\author{
Feras Hussein Shatat ${ }^{1}$, Osamah (Mohammad Ameen) Aldalalah ${ }^{2} \&$ Ziad Waleed Ababneh $^{3}$ \\ ${ }^{1}$ Emirates Collage of Technology (ECT), Abu Dhabi, UAE \\ ${ }^{2}$ Department of Educational Technology, Jadara University, Jordan \\ ${ }^{3}$ Abu Dhabi Education Council, Abu Dhabi, UAE \\ Correspondence: Feras Hussein Shatat, ECT, Abu Dhabi, UAE. E-mail: ferasshatat@gmail.com
}

Received: November 5, 2016

Accepted: December 26, 2016

Online Published: January 19, 2017

doi:10.5539/ass.v13n2p49

URL: http://dx.doi.org/10.5539/ass.v13n2p49

\begin{abstract}
The purpose of the present study was to examine the effects of E-book of the Pyramid Bloom levels on the Emirates College of Technology (ECT) students at both internal and external motivation levels. The business statistics unit developed in two different methods. This study utilized the quasi experimental type methodology. The independent variables were the methods, traditional and E-book. The dependent variables were the Pyramid Bloom levels, which will be determined by the final mark on the post-test. The moderator variables are motivation levels, internal and external. The study sample consisted of 61 undergraduate ECT students, and were randomly selected, via simple random sample, from 127 students. ANOVA procedure was used to determine the significant differences of the pretest scores among the two methods. An analysis of covariance, ANCOVA, was carried out to examine the main effects of the independent variables on the dependent variables. The findings of this study showed that students who have learned through the E-book method achieve design efficiently better in their post-test scores than those in the traditional method. Students at the internal motivation level perform design efficiently better in their post-test scores than those at external motivation level. The E-book method proved to help students with external motivation in their post-test score motivation.
\end{abstract}

Keywords: E-book, Pyramid Bloom, Motivation

\section{Introduction}

We care about the educational process at all levels, from the onset to the end of the learning process, because of its great importance in developing communities, and keeping with the pace of time, that is characterized by the ease in which information is accessed (Olsson, Mozelius, \& Collin, 2015). We have a different perception of the educational process from the past which primarily focused on feeding the student's mind with information, and expecting them to access and deliver this information during assessments, rendering this information temporary and disposable post assessment (Ulstad et al., 2016).

This approach encouraged teachers to focus on conservation rather than focusing on the application of knowledge (Nader, 2016). We now live in an era of statistics and facts, so the student's ability to apply this information is not only relevant, but vital (Stubbé et al., 2016). We have noticed a great interest in the higher levels of knowledge of the Bloom Pyramid in recent years, due to the increased number of people and the need for new products that encompass the needs of people and facilitate new job opportunities for the youth (Hubei, 2013). These circumstances have led to an increased interest in the top of Bloom's Pyramid (Junoh et al., 2011). Technological developments played a key role in such interests. Bloom employed all of the possible technologies to serve the educational process such as Blackboards, Moodle, Smart boards, and computers, which made way for diversified educational programs that proved to be cost effective and practical within educational context. Education was no longer restricted to classrooms, it encompassed all suitable times and places, such as playgrounds and libraries, empowering students with exciting learning opportunities within diverse settings (Kruger \& Bester, 2014).

The concept of mathematics includes calculations, numerical operations, and measurement. It also includes the 
use of engineering and algebra alongside with the ability to think and solve problems through the use of concepts, symbols, rules, and quantity theories (Aydın, 2005). Mathematics is a comprehensive concept beyond arithmetic, as mathematics is comprised of concepts, terminologies, symbols, skills, and problem solving. Symbols, terminologies and concepts are considered to be the foundation of mathematical knowledge that a student must comprehend to derive mathematical generalizations from theories (Sawalha, 2011). The ability to apply mathematical knowledge supports the student in undertaking and tackling any mathematical problem (Mojadl \& Yafei, 2009). Difficulties in learning mathematics are considered to be one of the hindering factors in the educational process, as these difficulties begin at the elementary stage and persists into the higher levels of education and beyond (Shubair, 2011). These difficulties may be attributed to the nature of abstraction and structure in mathematics, as it begins with simple concepts and develops into more complicated abstract concepts (Asha, Beqe'e, \& Al-Absi, 2014).

Many students feel uncomfortable learning mathematics, their dislike of mathematics becomes apparent when they display difficulties when attempting to solve a mathematical problem (Al-Majali et al., 2012). Studies reveal the relationship between students fear of mathematics and their performance in mathematics, hence it is very important to learn thinking skills and emphasize creativity (Sufiani, 2008).

\section{Study Problem}

The main focus of this study is to show evidence of the incompetency in current teaching methods in an effort to develop thinking processes in general and the cognitive processes of college students, particularly in mathematics and statistics. Although there is a continuous effort to develop the learning process, the scientific level of mathematics student hasn't amounted to what is expected, and the reason for this may be due to not focusing on taking advantage of new teaching methods. The researcher has developed this study during his teaching experience. This study came to investigate the teaching process and its effects on students. He divided the study into two learning models through designing mathematical lessons using the eBook strategy, and using the traditional book, which was used as his primary instructional tool. The traditional book served as a guide for his students, providing information and the explanation of concepts, while the student participated as a recipient of information and assumed a note taking role.

\section{Research Questions}

1. Will students using the E-book method attain significantly higher post test scores (PTS) than students using the traditional method?

2. Will students with internal motivation attain significantly higher post test scores than external motivation?

3. Will students with external motivation using the E-book method attain significantly higher post test scores than external motivation students using the traditional method?

4. Are there interaction effects between treatment methods and motivation on the posttest scores?

\section{Research Framework}

Figure1 shows the relationships between the different variables below.

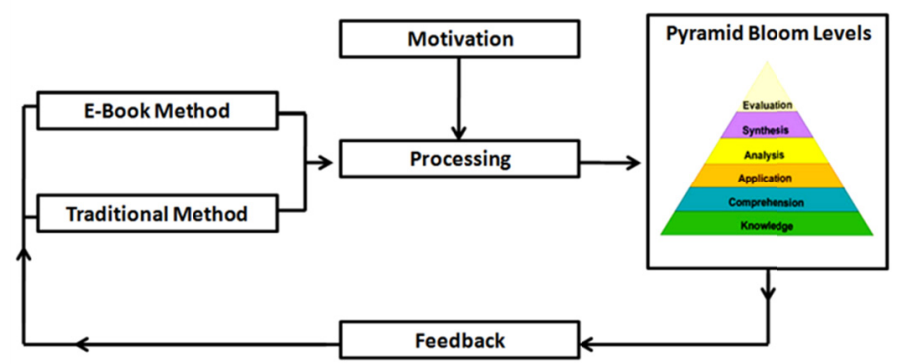

Figure 1. Research Framework

The research framework depicts three variables. The independent variables include the E-book method and traditional method. The dependent variables are Pyramid Bloom levels. The moderator variable is motivation levels. The framework that is presented in this study has a strong contingent effect on the relationships between the independent and dependent variables. The effect of using the E-book on learning will be identified by measuring Pyramid Bloom levels in business statistics courses. There are two main objectives of this study:

1. Evaluating the impact of E-book on the Pyramid Bloom levels of business statistics courses. 
2. Conducting an aptitude treatment, motivation, to investigate the possible interaction effects of the aptitude of the students in the two methods.

\section{Background}

\subsection{Bloom's Pyramid of Learning}

The main duty of teachers in the learning and teaching process is planning (Barakat \& Sabah, 2007). This includes many procedural steps that are relevant to designing educational models, such as writing the educational goals that vary from general educational goals to behavioural goals (McKenney \& Visscher-Voerman, 2013).

Educational scientists encourage teachers to write educational goals that stem from their interests in developing a student's way of thinking and preparing him to think creatively (Hawks, 2010), which helps him to serve himself and his society in a productive manner (Al-Sarayreh, 2011). Writing comprehensive educational goals helps teachers to choose suitable teaching methods, educational aids, educational activities and exam assessments (Darwazeh, 2011).

Educational goal is defined as a statement that describes what the learner does after an educational experience (Barakat \& Sabah, 2007), it is a well known fact that educational goals are expected from the students after the learning process, and his behaviours will indicate his learning, that which has been employed in his mental activities and thinking process (Nayef, Yaacob, \& Ismail, 2013). Educators view the learning process as a complete and comprehensive process of dividing educational goals into three stages, however it was limited to particular subject areas (Christi, 2012). Whereas, Bloom's classification is more suitable because it can be used with all subjects (Seddon, 1978).

In 1956 Benjamin, of Chicago University, divided educational goals into three categories Cognitive, self-kinesthetic and emotional (Darwazeh, 2001). Bloom's pyramid is considered one of the oldest frameworks which is based on mental activities (the cognitive performance for the educator) for the educators and what followed these activities from mental processes, and shows the levels of goals that can be designed (Hubei, 2013). The Bloom's pyramid model divides knowledge into six levels.

These levels of cognitive include, knowledge, Comprehension, Application, Analysis, Synthesis and Evaluation (Junoh et al., 2011). Knowledge refers to the individual ability to remember what he learnt, previous information, concepts, realties, vocabulary, names and dates (Alawneh, 2009). Comprehension, means the ability of the learner to realize what he had learned, shall be able to explain which he learned and summarized and interpreted (Kastberg, 2003). Application is the educator's ability to perform realize what he has learnt (Hawks, 2010). The Analysis shows an educator's ability to analyse the learning material into small fragments, to know the reasons and motivations and to link between elements; learner at this stage have the ability to conclude and to understand the relationship between cause and effect (Junoh et al., 2011). Synthesis refers to the learners ability to collect data and to group elements together in a different sequence, and to provide new solutions by developing plans and processes (Forehand, 2005). Evaluation refers to the learner's ability to judge the value of anything according to a set of standards, the learner is able to provide a point of view, his judgment and he is able to form conclusions, provide ideas, and defend these ideas (Kastberg, 2003).

Remembering is placed at the bottom of Bloom's pyramid, whereas assessment is positioned at the top of the pyramid because it is very complicated (Barakat \& Sabah, 2007). The learner must possess a complete understanding of the bottom most levels before graduating to the uppermost levels within the pyramid. This system enables educators to diversify educational goals (Al-Sarayreh, 2011). Given the scientific subjects such as Mathematics provides the learner with different thinking styles. These thinking styles include inductive, deductive, abstract, scientific and creative styles of thinking (Al-Jarrah et al., 2014).

\subsection{Motivation}

A group of situations motivates the learner to achieve goals (Al-Jarrah et al., 2014). This situation usually affects on individual behaviour as it increases the continuity of the behaviour to achieve the required goals (Hadeh, 2013). The motivation activates and directs human behaviour (Negovan \& Bogdan, 2013). Many factors effect individual behaviours such as the ability to perform the behaviour and the availability of suitable circumstances, even if such circumstances are available, it doesn't guarantee the persistence of the behaviour, rather it depends on the level of an individual's motivation (Salem, Kabylie, \& Khalefah, 2012). The motivation for learning has two types, the first one is internal and the second is external (Al-Silami, 2015). The external motivation derived from some external factors such as the diversity of the surrounding environment, teaching strategies, and the diversity in learning resources (Dudin \& Jerwan, 2012). In addition to social circumstances to facilitate respect for others, a reward and punishment strategy is implicit, because learners want to learn as a result of 
encouragement and to avoid punishment (Alwan \& Atteat, 2010)

The internal motivation, as defined by Bencsik, Mechova \& Hevesi (2016), is done by the individual himself without any external encouragements. Lin-Siegler, Ahn, Chen, Fang \& Luna-Lucero (2016) views it as the individual wish to perform a job in the job itself, the source of this type of motivation is the individual himself. We notice that individuals learn best when they are eager to learn when interested and feel comfortable while during the learning process (Vibulphol, 2016). The learners in this mindset are eager to have undertaken new experiences, intake knowledge, and skills that are suitable with their personalities (Ulstad et al., 2016). Educators work to show these learners how to learn, so they can have a continuous, self-engaged approach to learning (Cho, 2013). Educators usually try to switch from external learning to internal learning, because learners are motivated by their needs to learn without an outside motivator to achieve self-esteem (Huang \& Hew, 2016).

\subsection{E-book}

Computers have a huge effect in all areas of life, including education (Olalekan \& Oludipe, 2016). Computers are characterized by storing substantial volumes of knowledge (Nader, 2016). They've become a portable library, especially with the use of laptops, the internet, and communication technologies (Eaz, 2014). As a result, E-books have become widespread among the masses (Mohammadi, 2012). E-books are relatively easy to operate and to read, because they have multimedia materials such as videos, pictures, colour full texts and audio materials (Saleh, 2011). Producing and publishing E-books are relatively cost-efficient, and they also contain hyperlinks to supplementary materials (Shennan \& Shaya, 2009).

Traditional books and eBooks have commonalities, such as the availability of a reading resource at the fignertips of students (Hussain, 2013). However, E-books but have an advantage over traditional books during classroom lessons, as teachers are able to communicate with students, such as providing timely feedback during lessons (Biranvand \& Khasseh, 2014). Students can use more than one sense while using eBooks, because eBooks are bursting with diverse multimedia materials, and shy students will have greater opportunities to pose questions to their teachers without worrying about judgment been passed to them by their peers (Chen, Fan, \& He, 2012).

Types of E-books have differed greatly, there are text eBooks, visualized eBooks, and multimedia e-Books. There are currently two common eBook designs. Firstly, the PDF format that could be read on computers with no kind of modification of the text. Secondly, is the RTF format, this type of eBooks is read on computers and could be easily modified (Mohammadi, 2012).

As a result of the widespread use of computers and the internet, we have an emerging interest in eBooks in schools and universities (Al-Mashaqbeh \& Al Shurman, 2015). Computers have a huge effect on students' answers (Olalekan \& Oludipe, 2016). These institutions distribute eBooks to students on CDs or they can download any eBook from the internet and save them on their personal devices (Ebied \& AbdulRahman, 2015).

The definition of the E-book differs, depending on the design, the use, and the user. Shiratudd in, Landoni, Gibb and Hassan (2003) views eBooks as an application based on a database for multimedia such as videos, pictures, colourful texts, audios, scientific materials and metadata. Hussain (2013) views an E-book as a digital material for a written text, and can be read on devices such as computers or tablets. Ebied and Rahman (2015) views the E-book as the contents in the book and available for everyone in the form of digital material. E-books represent traditional books, but they are saved on personal computers and available on the internet via web pages, and employ multimedia materials to work in replace of tutors, and they sometimes include hypertexts (Al-Mashaqbeh \& Al Shurman, 2015).

\section{Methods}

This study utilized the quasi experimental type methodology to measure the impact of the two methods on the total achievement of the students in a Business Statistics course. This study includes one independent variables, one dependent variable, and one moderating variable.

\subsection{Study Sample}

The population of the study included all students enrolled in the Business Statistics course which consisted of 127 students enrolled in the Emirates College of Technology (ECT) in the first semester during the academic year 2015/2016. Arandom sample of 68 students was chosen for the study. A total of 61 students completed the study. The students were divided into 2 methods depending on the following:

The research sample was comprehensive so as to represent the population well in order to ensure the external validity of the study, which affects the process of results generalization. The population of this study almost represents all of the existing social classes in ECT. They ranged in age between 19 and 21 years. Also, they are 
homogenous in terms of their language, exposure to English as a foreign language, cultural, nationality, level of education and differences in gender.

Table 1. Distribution of 2 Methods

\begin{tabular}{|c|c|c|c|}
\hline \multirow{2}{*}{ Treatments } & \multicolumn{2}{|c|}{ Motivation } & \multirow{2}{*}{ Total } \\
\hline & Internal & External & \\
\hline Treatment $1 \quad$ E-Book & 14 & 17 & 31 \\
\hline Treatment 2 Traditional & 12 & 18 & 30 \\
\hline Total & 35 & 26 & 61 \\
\hline
\end{tabular}

\subsection{Research Variables:}

There are three types of variables in this study

(Independent, Dependent, Moderating variables) can be displayed as follows:

\subsubsection{Independent Variables:}

The method application; it has two treatments:

First Treatment: E-book

Second Treatment: Traditional

6.2.2 Dependent Variables:

Pyramid Bloom levels, which will be determined by the final mark on the post-test.

6.2.3 Moderator Variables:

Motivation (Internal, External) which will be classified as internal and external through motivational instrument.

\subsection{Study Instruments}

There are two instruments in this study, Business Statistics Achievement Test and Motivation Scale, both of which were used to assess the learners musical achievement.

\subsubsection{The Business Statistics Course Achievement Test (the pre-test and post-test)}

The business statistics course achievement test that was administered by the students' of the two method methods in this study was adapted from the Business Statistics Course Test developed by researchers. The Business Statistics Course Achievement Test consisted of 4knowledge, 4Comprehension, 5 Application, 4 Analysis, 4 Synthesis and 4 Evaluation. Items as shown in Table 1. The Business Statistics Achievement Course Test consists of 25 items, and the duration of the Achievement Business Statistics Course Test was 35 minutes.

Table 2. The number of Bloom's Taxonomy indicates the item number in the test.

\begin{tabular}{cccccccc}
\hline Topics & knowledge & Comprehension & Application & Analysis & Synthesis & Evaluation & $\begin{array}{c}\text { Numbers of } \\
\text { Goals }\end{array}$ \\
\hline $\begin{array}{c}\text { Uniform distribution } \\
\text { Properties of the }\end{array}$ & 14 & 2 & $11,18,24$ & 5,23 & & & 3 \\
$\begin{array}{c}\text { normal distribution } \\
\text { Normal distribution }\end{array}$ & $4,16,17$ & 7,13 & 25 & 6 & & $8,9,15$ & 1 \\
Total & 4 & 1 & 19 & 10 & $3,20,21,22$ & 15 & 3 \\
\hline
\end{tabular}

The achievement test comes in the following arrangement: The test is composed of six types of items. The six types are based on multiple-choice items for knowing, Comprehension, Application, Analysis, Synthesis and Understanding that are specifically designed to assess the learners business statistics course achievement. The test-retest way is utilized to be the majority suitable approach of measure the reliability of the achievement test. The length of time between the two tests in order to make reliable measurements of four weeks. The pre-test and post-test questions were similar in content used to evaluate the student's ability to gain what they understood from the lessons, and the topics covered in the first unit by reporting their learning achievement scores on the test. The focus was on the Bloom pyramid as shown in Figure 2. 


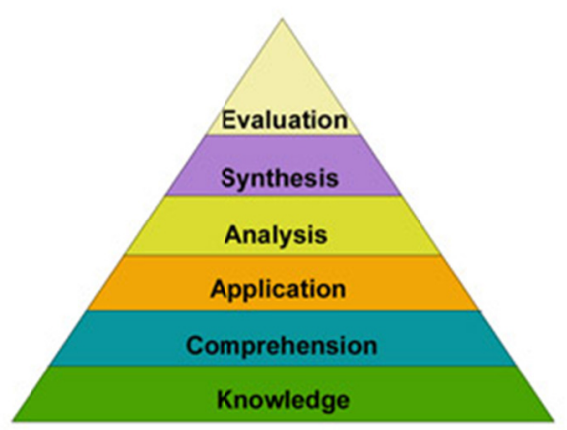

Figure 2. Bloom Pyramid

The test addresses Bloom's Pyramid for the students, where the test covers all of the contents ina textbook used for this grade. Table 3 shows the distribution targets in the cognitive test.

Table 3. Distribution of the (MKT) items for Continuous Probability Distribution

\begin{tabular}{|c|c|c|c|c|c|c|c|c|c|}
\hline $\begin{array}{l}\text { Cognitive } \\
\text { domains } \\
\text { Topics }\end{array}$ & Knowledge & Comprehension & Application & Analysis & Synthesis & Evaluation & $\begin{array}{l}\text { Items } \\
\text { Total }\end{array}$ & $\begin{array}{c}\text { Numbers } \\
\text { of Goals }\end{array}$ & Percentage \\
\hline $\begin{array}{l}\text { Uniform } \\
\text { distribution }\end{array}$ & 1 & 1 & 3 & 2 & 0 & 0 & 7 & 3 & $42.9 \%$ \\
\hline $\begin{array}{l}\text { Properties } \\
\text { of the } \\
\text { normal } \\
\text { distribution }\end{array}$ & 3 & 2 & 1 & 1 & 0 & 3 & 10 & 1 & $14.2 \%$ \\
\hline $\begin{array}{c}\text { Normal } \\
\text { distribution }\end{array}$ & 0 & 1 & 1 & 1 & 4 & 1 & 8 & 3 & $42.9 \%$ \\
\hline Total & $\begin{array}{c}4 \\
16 \%\end{array}$ & $\begin{array}{c}4 \\
16 \%\end{array}$ & $\begin{array}{c}5 \\
20 \%\end{array}$ & $\begin{array}{c}4 \\
16 \%\end{array}$ & $\begin{array}{c}4 \\
16 \%\end{array}$ & $\begin{array}{c}4 \\
16 \%\end{array}$ & 25 & 7 & $100 \%$ \\
\hline
\end{tabular}

The aggregate score of the Business Statistics Course Test is 25 . Students received a score of "1" for a right answer and a score of " 0 " for an erroneous answer or if no answer was given. To make sure the reliability of the Business Statistics Course Achievement Test Arabic edition (Table 4), the researchers applied a pilot study to check the reliability by a Test-Retest. The tests were divided into six parts; the reliability of the test question was calculated using the Coronach Alpha method to analyse the internal consistency.

Table 4. Distribution of the (MKT) items for Continuous Probability Distribution

\begin{tabular}{ccc}
\hline Parts & Cronbach Alpha & Internal Consistency \\
\hline Knowledge & 0.81 & 0.87 \\
Comprehension & 0.82 & 0.85 \\
Application & 0.83 & 0.81 \\
Analysis & 0.76 & 0.82 \\
Synthesis & 0.79 & 0.85 \\
Evaluation & 074 & 0.80 \\
Total & 0.79 & 0.83 \\
\hline
\end{tabular}

\subsubsection{Motivation Scale}

This instrument was used to all the students in the study to examine motivations. The Researchers have adopted this questionnaire from Hedah (2013). The questionnaire consists of 20 items and was composed of two subsections internal motivation (ability and effort) versus external motivation (parents, teacher, etc.) factors which affect the outcomes. The total score of the motivation scale test is 100 . These items were rated using a 5 
point Likert Scale with the following anchors: $1=$ Strongly Agree; $2=$ Agree; $3=$ Neutral; $4=$ Disagree; and $5=$ Strongly Disagree for an external answer and Strongly Disagree $=1$; Disagree $=2$; Neutral $=3 ;=4$ and Strongly Agree $=5$ for an internal answer and ' 0 " in case of non-response on each item. Students' motivation was separated into two levels (External and Internal) using the following equation:

Lowest Mark $=\mathbf{L}_{\boldsymbol{m i n}} /$ Highest Mark $=\mathbf{H}_{\text {min }}$

$$
Z=\frac{\text { Highest Mark }- \text { Lowest Mark }}{\text { Nnumberof Levels }}
$$

The difference between levels and the other $=\mathbf{Z} / \quad$ Internal $=\mathbf{I} \quad /$ External $=\mathbf{E}$

$\mathrm{I}($ range $)=\left[\mathbf{L}_{\min }+\mathrm{Z}-\mathbf{L}_{\min +2 \mathrm{Z}}\right] \quad / \quad \mathrm{E}($ range $)=[$ Lmin-Lmin $+\mathrm{Z}]$

Number of Levels $=2$ / Lowest Mark $=33$ / Highest Mark $=95$

$Z=\frac{95-33}{2}=31 \quad \mathrm{E}($ range $)=[33-64]$
$\mathrm{I}($ range $)=[65-95]$

In any study, research instruments validity and reliability are two important aspects that should be taken into account when conducting a research study. The researchers used Test-Retest to check the reliability of the Arabic version scale, the reliability factor was calculated by Alpha Cronbach where Alpha was 0.72 for the whole scale. And the internal consistency in this scale was 0.84 . Validity consist two different aspects are face and content validity. Content validity of the instruments in this research study was justified by the panel. During and after the development of this study the instruments were evaluated. The notes and feedback received from the specialists were working to find the basic changes, clarifications and adjustments before and after the study workout.

\section{Results}

\subsection{Method's Equivalence}

The purpose of present pre-experimental study was to assess the assumption that the participants across the two method methods were equivalent business statistics course. To reach this aim, a pre-test that measures prebusiness statistic scores were conducted before the start of the study. To analyse if the equality of treatment on pre business statistic scores using the ANOVA process (Table 5\&6)

Table 5. ANOVA of the Pre-test Scores to Measure the Equality of Methods

\begin{tabular}{cccccc}
\hline & Sum of Squares & df & Mean Square & F & Sig. \\
\hline Between Methods & .262 & 1 & .262 & .019 & .891 \\
Within Methods & 811.738 & 59 & 13.758 & & \\
Total & 812.000 & 60 & & & \\
\hline
\end{tabular}

Table 5 presents the results of ANOVA test, The values $\mathrm{F}(1,59)=.019$, Mean Square $=.262$, and $\mathrm{p}=.891$ which showed that there is no significant difference in the pre test scores in various treatment methods. This means that methods equal.

Table 6. ANOVA of the Pre-test Scores to Measure the Equality of Motivation Methods

\begin{tabular}{cccccc}
\hline & Sum of Squares & df & Mean Square & F & Sig. \\
\hline Between Methods & 11.109 & 1 & 11.109 & .818 & .369 \\
Within Methods & 800.891 & 59 & 13.574 & & \\
Total & 812.000 & 60 & & & \\
\hline
\end{tabular}

Table 6 showed the results of ANOVA test, The values $F(1,59)=.818$, Mean Square $=11.109$, and $p=.369$ which presents that there is no significant difference in the pre test scores in different motivation methods. This means that methods equal.

\subsection{Measuring Normal Distribution and Homogenization}

Measurement of homogeneity and normal distribution has been among the methods account, and the level of motivation on the pre and post tests, the Table 7 shows the level of homogeneity. 
Table 7. The level of homogeneity

\begin{tabular}{lc}
\hline The study sample & Sig. \\
\hline Methods on the pretest & .780 \\
Methods on the post-test & .132 \\
Motivation to pretest levels & .691 \\
Motivation on the post-test levels & .137 \\
\hline
\end{tabular}

Table 7 shows all homogeneous study methods on all variables. The data also show that they follow a normal distribution of the pre and post tests. Thus, the results will be ready to analyse and show the results of the study questions.

\subsection{Question 1}

Will students using the eBook treatment attain significantly higher post test scores (PTS) than students using the traditional treatment?

\section{The result of students' achievement}

Table 8. Descriptive of the Post-test Scores of Students with Different Methods (Traditional, eBook)

\begin{tabular}{llll}
\hline Methods & Mean & Std. Deviation & $\mathrm{N}$ \\
\hline Traditional & 14.2000 & 4.02064 & 30 \\
E-Book & 19.2903 & 3.01323 & 31 \\
Total & 16.7869 & 4.35168 & 61 \\
\hline
\end{tabular}

Table 8shows that the mean of post-test scores $(\mathrm{m}=19.2903)$ for the E-book method is higher than the mean of post-test scores $(\mathrm{m}=14.2000)$ for the traditional method. A comparison was made between the methods using the ANCOVA test procedure (Table 9).

Table 9. ANCOVA of the Post-test Scores of Students with Different Methods (Traditional, E-Book)

\begin{tabular}{cccccc} 
Source & Type III Sum of Squares & df & Mean Square & F & Sig. \\
\hline Corrected Model & $395.118(\mathrm{a})$ & 2 & 197.559 & 15.461 & .000 \\
Intercept & 2917.730 & 1 & 2917.730 & 228.344 & .000 \\
pre-test & .075 & 1 & .075 & .006 & .000 \\
Methods & 394.719 & 1 & 394.719 & 30.891 & .003 \\
Error & 741.112 & 58 & 12.778 & & \\
Total & 18326.000 & 61 & & & \\
Corrected Total & 1136.230 & 60 & & & \\
\hline
\end{tabular}

R Squared $=.348$, Adjusted R Squared $=.325$

Table 9 shows that there was a significant difference between the methods, in favor of the experimental (eBook) method.

\subsection{Question 2}

Will students with internal motivation attain significantly higher post test score than external motivation?

The result of students' achievement

Table 10. Descriptive of the Post-test Scores of Students with Different Levels of Motivation (I \& E)

\begin{tabular}{cccc}
\hline Motivation & Mean & Std. Deviation & $\mathrm{N}$ \\
\hline Internal & 19.5517 & 3.07741 & 29 \\
External & 14.2813 & 3.80352 & 32 \\
Total & 16.7869 & 4.35168 & 61 \\
\hline
\end{tabular}


Table 10 shows that the mean post-test score for internal motivation method $(\mathrm{m}=19.5517)$ is higher than the mean post-test score for the external motivation method $(\mathrm{m}=14.2813)$. A comparison was made between the methods using the ANCOVA test (Table 11).

Table 11. ANCOVA of the Post-test Scores of Students with Different Levels of Motivation Methods (I \& E)

\begin{tabular}{cccccc}
\hline Source & Type III Sum of Squares & df & Mean Square & F & Sig. \\
\hline Corrected Model & $425.775(\mathrm{a})$ & 2 & 212.887 & 17.380 & .000 \\
Intercept & 3136.898 & 1 & 3136.898 & 256.090 & .000 \\
Pretest & 3.186 & 1 & 3.186 & .260 & .612 \\
Motivation & 425.376 & 1 & 425.376 & 34.727 & .000 \\
Error & 710.455 & 58 & 12.249 & & \\
Total & 18326.000 & 61 & & \\
Corrected Total & 1136.230 & 60 & & \\
\hline
\end{tabular}

$(\mathrm{R}$ Squared $=.375$, Adjusted R Squared $=.353)$

Table 10 showed that there was a significant difference between the levels of Motivation methods (I \& E), in favour of the Internal method.

\subsection{Question 3}

Will students with external motivation using the E-book treatment attain significantly higher post test scores than external motivation students using the traditional treatment?

The result of students' achievement

Table 12. Descriptive of Post Test Scores of External Motivation Students in Various Methods

\begin{tabular}{cccc}
\hline Methods & Mean & Std. Deviation & $\mathrm{N}$ \\
\hline Traditional & 11.7222 & 2.29592 & 18 \\
E-Book & 17.5714 & 2.62281 & 14 \\
Total & 14.2813 & 3.80352 & 32 \\
\hline
\end{tabular}

Table 12 it showed that the mean post-test score $(m=17.5714)$ for the E-book method is higher than the mean post-test score $(\mathrm{m}=11.7222)$ for the traditional method. A comparison was made between the methods using the ANCOVA test procedure (Table 13).

Table 13 showed that there was a significant difference between the methods in favor of the experimental (eBook) method

\begin{tabular}{cccccc}
\hline Source & Type III Sum of Squares & df & Mean Square & F & Sig. \\
\hline Corrected Model & $282.083(\mathrm{a})$ & 2 & 141.041 & 24.583 & .000 \\
Intercept & 1562.440 & 1 & 1562.440 & 272.323 & .000 \\
Pretest & 12.654 & 1 & 12.654 & 2.205 & .148 \\
Methods & 280.062 & 1 & 280.062 & 48.813 & .000 \\
Error & 166.386 & 29 & 5.737 & & \\
Total & 6975.000 & 32 & & & \\
Corrected Total & 448.469 & 31 & & &
\end{tabular}

$(\mathrm{R}$ Squared $=.629$, Adjusted R Squared $=.603)$

Table 13 showed that there was a significant difference between the methods in favor of the experimental (eBook) method.

\subsection{Question 4}

Are there an interaction effect between methods and motivation on the post- test score? 


\section{(a) Descriptive of the Post Score by Motivation for Methods}

Table14 represents the overall mean and standard deviations of each post score by the interaction between the methods and (internal and external) motivation. The mean scores of the traditional method show internal motivation $(\mathrm{m}=17.9167)$ external motivation $(\mathrm{m}=11.7222)$. The mean scores instructed for the E-book method reported an internal motivation of $(\mathrm{m}=20.7059)$ and external motivation $(\mathrm{m}=17.5714)$.

Table 14. The Mean Score and Standard Deviation of the Post Score by Motivation for Method

\begin{tabular}{ccccc}
\hline Methods & motivation & Mean & Std. Deviation & $\mathrm{N}$ \\
\hline Traditional & Internal & 17.9167 & 3.05877 & 12 \\
& External & 11.7222 & 2.29592 & 18 \\
& Total & 14.2000 & 4.02064 & 30 \\
\multirow{2}{*}{ E-Book } & Internal & 20.7059 & 2.59241 & 17 \\
& External & 17.5714 & 2.62281 & 14 \\
& Total & 19.2903 & 3.01323 & 31 \\
& Internal & 19.5517 & 3.07741 & 29 \\
& External & 14.2813 & 3.80352 & 32 \\
\end{tabular}

\section{(b) ANCOVA of Interaction Effect between Methods and Motivation}

To examine if the effects of Methods on post score depend on the motivation level in Traditional method, and in eBook method, while controlling pre-score, multivariate analysis of covariance (ANCOVA) was conducted.

Table 15. ANCOVA for motivation by Interactional Methods

\begin{tabular}{ccccccc}
\hline Source & Type III Sum of Squares & df & Mean Square & F & Sig. & Partial Eta Squared \\
\hline Corrected Model & $753.761(\mathrm{a})$ & 4 & 188.440 & 27.591 & .000 & .663 \\
Intercept & 3137.741 & 1 & 3137.741 & 459.420 & .000 & .891 \\
Method * Motivation & 38.584 & 1 & 38.584 & 5.649 & .021 & .463 \\
Pretest & 7.017 & 1 & 7.017 & 1.027 & .315 & .420 \\
Method & 276.596 & 1 & 276.596 & 40.498 & .000 & .092 \\
Motivation & 330.170 & 1 & 330.170 & 48.343 & .000 & .018 \\
Error & 382.468 & 56 & 6.830 & & & \\
Total & 18326.000 & 61 & & & & \\
Corrected Total & 1136.230 & 60 & & & & \\
\hline
\end{tabular}

$(\mathrm{R}$ Squared $=.663$, Adjusted R Squared $=.639)$

The results of ANCOVA test (Table 15) presents the results of ANCOVA test, viewing generally differences for the interaction between method and motivation level effects on the post score, while calculating the pre-score. The ANCOVA results of the interaction effects on the post score were statistically significant $F(1,56)=5.649, \mathrm{p}$ $=.021$. This interaction accounted for $5 \%$ of the variance of the students' learning $($ Eta $2=.463)$.

\section{Results Discussion}

8.1. Will Students Using the E-book Treatment Attain Significantly Higher Post Test Scores (PTS) Than Students Using the Traditional Treatment?

Researchers explain this result in relation to the Bloom's pyramid in the two methods, but the experimental method, which was taught using eBooks, was above the control method which was taught using the traditional book. These results may be due to the learning material was presented when using eBooks. There are links between the abstract theoretical knowledge and application, and this may have a profound educational effect on traditional books, as it enables students to solidify concepts that lead to increased educational achievement.

It may be due to the design of the electronic books, as a student may not lose time in the text, because students 
will have clear goals that they want to achieve, the educational content, the educational activities, exercises, videos, to reach the assessment questions and to get the direct feedback. Teachers in the traditional learning may forget to motivate students directly.

Electronic books permit special needs students to continue their education without facing the social embarrassments when making mistakes. This is not available in traditional books because many students evade participation in classrooms. Electronic books differentiate between students' abilities, changing these differences into time differences, then students react to electronic books, according to one's ability without the interference of others.

Electronic books gave many students the chance to avoid isolation in relation to time and geography. The educational material could be downloaded at any time and place, students are also able to surf the internet and visit libraries in different countries and download any material they want to read.

Electronic design played a great role in motivating students, and to increase the focus of students on educational material. Students, while reading an electronic book may use more than one sense, studies showed that if any student uses more than one sense the understanding is greater.

Enthusiasm in using eBooks may result in more attraction to the learning process, the learner is not only an active part and recipient of information, but he is active in discussions with the teacher and in self-learning. This type of learning provide the student with the opportunity to read actively by using the electronic book more than one time as a result of the interesting material in it.

This type of learning has a lot of benefits, the researcher's view that the electronic book provided students with the basis of statistics taking into consideration the design of titles, words in a clear and interesting way for the learners.

Other researchers relate that other factors such as: the role of technological development in the education process, and that computers are key in this development. Many researchers show that students who learn languages, verbal and written, with the help of computers may retain their acquired language for a long period of time when compared to the traditional way.

Education goals are clear and they are arranged in a logical order. Another reason is telling students about the time available to use the electronic book, and to provide students with most important concepts and skills that students have to focus on and to achieve during the educational process, and to clarify steps and responsibilities of students, how to evaluate self-learning by using computers, in addition to determine the activities that students should do to acquire learning through eBooks.

The researchers attribute this result to the large number of exciting factors, within the eBook, including the colour, which helped to draw the attention of the learner. Also the organization of the electronic book had a major role in understanding the content. These are among the factors that have contributed directly to the eBook method of creating effective learning, as well as repeating the stimuli and responses in the learning programs and the guidance of the teacher.

All of the before mentioned prove how students can actively interact which enables them to better retain knowledge, in addition to that, hard work may have been a role to gain more attraction and to continue studying the lessons. Researchers reported that students work performance increased when using the eBooks in the post test, while poor results appeared with students used the traditional book.

\subsection{Will Students with Internal Motivation Attain Significantly Higher Post Test Score than External Motivation?}

Results have shown that there were more internal motivated students than external motivated students, and that may be due to students love to their work is affected by their orientations toward it. This love may have been attributed to many factors, such as: love to achieve high results, respect and self-esteem, the feeling of responsibility, and to increase development in their own life. Results shown that students with internal motivation have achieved results better than students with external motivation as a result of the close relation between motivation and achievement.

The result may be due to the relationship between students and their eagerness to participate in order to achieve higher education that satisfy their needs to prove self esteem in comparison with external motivation whose aim is to satisfy other people and to gain rewards.

Internal motivation is the best indicator of student achievement, so it is very important to know the relationship between the achievement and their motivation to learn. Researchers have reported that when motivation increased there will be high achievement. Learning will also increase students' understanding of their goals and 
we will notice a high level of planning, enthusiasm, and personal interaction in the educational process.

It can be interpreted that the students of internal motivation, focus on the individual and self-learning, and attribute their success and achievements to their abilities and their own efforts, and therefore they tend to master the tasks on their own without the help of others. In addition, students who have a high internal motivation to learn more effectively, and investigating deeper scientific issues, increase their efficiency and ability, and have a desire to master the challenging tasks and enjoy academic work. They usually set high goals for themselves as they look to their past experiences as an indicator for high potential, and also look at their failures as a challenge to overcome. These students are doubling their efforts, and attributing their successes and failures to internal factors.

\subsection{Will Students with External Motivation Using the eBook Treatment Attain Significantly Higher Post Test Scores than External Motivation Students Using the Traditional Treatment?}

Results revealed that students with external motivation who learned with the electronic book gained higher results than external motivated students who used the traditional book.

This result may be due to the what is included in the E-book, this result was attributed to the eBook from the exploitation of multimedia (text, images, sound and video clips). The learner is able to control the text in many ways and re-train with exercises, videos, audio and explanatory notes and students can make their own modifications when required. Students can also make use of the eBook on making a summary of the article in the eBook by cutting and pasting in a special file which time and effort provides the ability to refer to these summaries easily.

E-books offer the possibility to be broken into parts with the possibility of retrieving and reviewing the questions and examples. Where is the review process, the method of auditing, good accurate summary of the educational material, convert these summaries and titles of the questions increase the understanding of the educational material improves their studies and their achievement in examinations.

E-books display the learners continuous and direct reinforcement, which creates a challenge for the student to earn complacency, but, the traditional method may not provide it. Also, the diversity of assessment methods provided by the eBook leads to the reduction of student anger when experiencing failure to achieve learning goals. On the other hand, students experience positive feelings within conditions that encourage students to study using multimedia, which enables the learner with opportunities to achieve success and independently reach goals.

The level of shyness disappears because the students are trained and receive feedback individually with a high degree of privacy away from the frustrating irony learner learns of his own poetic independence and positivity towards learning. E-book encourages students to try and exert maximum effort and bear the frustration and support their attempts to understand and avoid criticism and satire, and helped them solve the problems they face, and by showing many examples and exercises related to the content of educational material. This may work on teaching students how to focus their attention and how to end the thing that they started it and they learn to study and experiment and the application of skill. E-book also takes into account individual differences among students, the learner is an official observer for himself.

\subsection{Is There a Relationship between Treatment Treatments and Motivation on the Post- Test Score?}

The present study found that the E-book method students with external motivation benefited more than their counterparts who possess the same characteristics but were taught using traditional approaches.

E-book plays a significant role in enhancing learning of students with low abilities. The eBook depended on the interaction between two channels. In a systematic mental activity, the content that is displayed the AI way stimulated systematic thinking and interaction. The students could thereby retrieve the data more easily. On the other hand, students with low abilities were in need of a teaching method that responds to their individual differences and processing ability of students. Therefore, students with low abilities were in need of a teaching method that considered their characteristics. The eBook treatment was helpful for such student as they displayed content with new knowledge being integrated into their previous knowledge.

\section{Recommendations and Implications for Future Research}

The findings of the study suggest some areas for future research:

1. Researchers should design and develop more Pyramid Bloom levels in business statistics course integrating eBook.

2. Researchers should conduct the eBook for a longer time period. 
3. Researchers should integrate eBook into the design and development of other fields in business statistics course.

4. This study used motivation students as a moderating variable in manipulating the effects of the independent variable on the dependent variables; future research should include other moderating variables, such as, cognitive style, learning style, pupils' ability, IQ and ability level.

5. No formal qualitative research like observations or interviews were conducted in this study. It would be particularly interesting to examine the individual experiences in the use of the eBook.

6. Studies should be conducted on the application of the modality and redundancy principles in emerging technologies such as mobile technology.

\section{Summary and Conclusions}

This study found that the use of the eBook method helped students perform significantly better in Pyramid Bloom levels of business statistics course. It gives support to the effect of eBook on the Pyramid Bloom levels of business statistics course. So, this study results strongly indicated that an E-book was viable in promoting a better business statistics course.

It is suggested that eBook be integrated into all courseware on the learning of business statistics course.The study also found that internal motivation students significantly performed better than external motivation students respectively. Furthermore, the learning of business statistics course among external motivation students was significantly better when they interacted with the E-book method.

Generally, all of the students responded favourably to Pyramid Bloom levels of business statistics course using eBook -based multimedia courseware.

\section{References}

Alawneh, O. (2009). Bloom's Taxonomy of the upper levels of knowledge in the development of achievement and the development of critical thinking in the Islamic Education. Jordan: Imad Eddin Publishing and Distribution.

Al-Jarrah, A., Muflih, M., Al-Rabee, F., \& Ghawanmeh, M. (2014). The Effect of Teaching by Instructional Software on Improving Maths Learning Motivation among 2nd Basic Graders in Jordan. Jordan Journal of Science in Education, 10(3), 261- 274.

Al-Majali, M., Al-Nsour, Z., Hamad, M., Hattab, K., Al-Zboon, H., \& Al-Matari, R. (2012). A Comparative Study of the Degree of the Use of Mathematic, Arabic Language and English Language Teachers to the Comuterized Carriculum on E-Learning System EduWave in Exploratory Schools. Studies. Educational Sciences, 39(1), 171-194.

Al-Mashaqbeh, I., \& Al Shurman, M. (2015). The Adoption of Tablet and e-Textbooks: first grade corecurriculum and school administration attitude. Journal of Education and Practice, 21(6), 188-194.

Al-Sarayreh, A. (2011). An Analytical Study of the citizenship of Achievement test Questions Amongst Social and National Education Teachers for 4th and 5thGrades at Southern Al-Mazar Directorate of Education (Unpublished master's thesis). Mu'tah University, Jordan

Al-Silami, T. (2015). Levels of Academic Procrastination and Self-Motivation and the Relationship between them among Students of Makkah and Laith Colleges in Saudi Arabia. Journal of Educational and Psychological Sciences, 16(2), 639-664.

Alwan, A., \& Atteat, K. (2010). The Relationship between Academic Intrinsic Motivation and Academic Achievement of A sample of Tenth grade in Ma'an City in Jordan. Islamic University Journal (Humanities Series), 18(2), 683-717.

Asha, I., Beqe'e, N., \& Al-Absi, M. (2014). Levels of Difficulties to Learn Mathematics from the Perspective of Practicum Students: Students' Suggestions and Solutions (College of Educational Sciences and Arts UNRWA). Journal of Taibah University for Educational Sciences, 9(2), 215-229.

Aydın, E. (2005). The use of computers in mathematics education: a paradigm shift from "computer assisted instruction" towards "student programming". The Turkish Online J. of Educational Technology, 4(2), 27-34.

Barakat, Z., \& Sabah, A. (2007). The Final Examinations Questions at Al-Quds Open University and the Extent Their Fulfillment of Bloom Taxonomy. Al-Quds Open University Journal for Research and Studies, 9(1), 124-156. 
Bencsik, A., Machova, R., \& Hevesi, E. (2016). The Relation between Motivation and Personality Types. International Business Management, 10(3), 183-193

Biranvand, A., \& Khasseh, A. A. (2014). E-book Reading and its Impact on Academic Status of Students at Payame Noor University, Iran. Library Philosophy and Practice (e-journal). Paper 1170.

Chen, Y.-L., Fan, S., \& He, Z. (2012). Exploratory Research: The Effects of Electronic Books on College Students. MBA Student Scholarship. Paper 14. Retrieved from http://scholarsarchive.jwu.edu/mba_student/14

Cho, Y. (2013). L2 learning motivation and its relationship to English proficiency: A causal analysis of university students' EIL discourses. English Teaching, 68(1), 37-68.

Christi, N. V. (2012). An Interpersonal Skills Learning Taxonomy for Program Evaluation Instructors. Journal of Public Affairs Education, 18(4), 741-756.

Darwazeh, A. (2011). The Degree that the Qalqilia Schools' Teachers Consider the "Bloom's Taxonomy" in Cognitive Domain when they Planning for Teaching. Najah University Research Journal (Humanities), 25(10), 2559-2582.

Dudin, T., \& Jerwan, F. (2012). The effect of acceleration andenrichment programs on the learning motivation, achievement and self esteem of gifted students in the higher basic grades in Jordan. Al-Quds Open University Journal for Research and Studies, 29(2), 105-148.

Eaz, H. (2014). Proposed training program to develop the use of faculty members to Tools virtual classroom Egyptian university e-learning (Unpublished Master's Thesis). Cairo University, Egypt.

Ebied, M., \& AbdulRahman, S. (2015). The effect of interactive E-book on students' achievement at Najran University in computer in education course. Journal of Education and Practice, 19(6), 71-82.

Forehand, M. (2005). Bloom's taxonomy: Original and revised. In M. Orey (Ed.), Emerging perspectives on learning, teaching, and technology. Retrieved from http://epltt.coe.uga.edu/

Hawks, K. (2010). The Effects of Implementing Bloom's Taxonomy and Utilizing the Virginia Standards of Learning Curriculum Framework to Develop Mathematics Lessons for Elementary Students (Unpublished doctoral dissertation) Liberty University.

Hedah, L. (2013). Relationship of academic achievement with adolescent learning motivation (Unpublished Master's Thesis). University Aklimohandoulhaj. Algeria

Huang, B., \& Hew, K. (2016). Measuring learners' motivation level in massive open online courses. International Journal of Information and Education Technology, 6(10), 759-764.

Hubei, R. (2013). Analysis of public exam questions for Arabic language of the stages of public education in Iraq in light of Bloom's Taxonomy (Unpublished Master's Thesis). University of Diyala.

Hussain, G. (2013). The effect of using an electronic book in the development of the electronic scheduling skills to middle school students (Unpublished Master's Thesis). Cairo University, Egypt.

Junoh, A., Muhamad, W., Abu, M., Jusoh, M., \& Desa, A. (2012). Classification of Examination Marks according to Bloom's Taxonomy by Using Binary Linear Programming. Paper presented at the 2012 International Conference on Innovation and Information Management (ICIIM 2012), Singapore.

Junoh, A., Muhammad, W., Ghazali, N., Jaafar, W., Saad, S., \& Aluwi, S. (2011). Allocation Marks Model for Examination Based on Bloom's Taxonomy. Paper presented at the International Conference on Modeling, Simulation and Control (IPCSIT 2011), Singapore.

Kastberg, S. (2003). Using Bloom's Taxonomy as a Framework for Classroom Assessment. Mathematics Teacher, 96(6), 402-405.

Kruger, M., \& Bester, R. (2014). Integrating eLearning to Support Medical Education at the New University of Botswana School of Medicine. The Electronic Journal of e-Learning, 12(1), 52-76.

Lin-Siegler, X., Ahn, J., Chen, J., Fang, F., \&Luna-Lucero, M. (2016). Even Einstein Struggled: Effects of Learning About Great Scientists' Struggles on High School Students' Motivation to Learn Science. Journal of Educational Psychology, 108(3), 314-328.

McKenney, S., \& Visscher-Voerman, I. (2013). Formal education of curriculum and instructional designers. Journal of the International Society for Design and Development in Education, 2(6), 1-20. 
Mohammadi, M. (2012). The effect of using an electronic interactive book proposal for a decision of systems analysis and design in the cognitive aspects and skill development for students of general education diploma PC Division (Unpublished Master's Thesis). Cairo University, Egypt.

Mojadl, A., \& Yafei, F. (2009). Learning difficulties of mathematics students first episode of primary education in Dhofar, from the perspective of math parameters "field study". Damascus University Journal, 25(3+4), 135-177.

Nader, A. (2016). Build an electronic environments based on some intelligent proxy patterns and measure its effectiveness on collection and trend toward her talented pupils have low educational attainment in preparatory (Unpublished doctoral dissertation). Ain-Shams University, Egypt.

Nayef, E., Yaacob, N., \& Ismail, H. (2013). Taxonomies of Educational Objective Domain. International Journal of Academic Research in Business and Social Sciences September, 3(9), 165-175.

Negovan, V., \& Bogdan, C. (2013). Learning Context and Undergraduate Students' Needs for Autonomy and Competence, Achievement Motivation and Personal Growth Initiative. Procedia-Social and Behavioral Sciences, 78, 300-304.

Olalekan, A., \& Oludipe, O. (2016). Effects of computer simulation instructional strategy on biology students' academic achievement in DNA replication and transcription. Asian J. of Educational Research, 4(2), 16-24.

Olsson, M., Mozelius, P., \& Collin, J. (2015). Visualisation and Gamification of e-Learning and Programming Education. The Electronic Journal of e-Learning, 13(6), 441-454.

Saleh, M. (2011). The effectiveness of electronic books for the treatment of learning disabilities, math the primary school pupils, Master Thesis (Unpublished). Ain-Shams University, Egypt.

Salem, H., Kabylie, K., \& Khalefah, A. (2012). The relationship between achievement motivation, locus of control, aspiration, and academic achievement among the students of higher education at Sudan. Arab Journal for the development of excellence, 4, 81-96.

Sawalha, A. (2011). Common Errors in Mathematics, Its Patterns for Students with Learning Disabilities in Mathematics Studies. Educational Sciences, 38(7), 2344-2365.

Seddon, G. (1978). The Properties of Bloom's Taxonomy of Educational Objectives for the Cognitive Domain. Review of Educational Research, 48(2), 323-303.

Shennan, A., \& Shaya, F. (2009). The effect of E-book on developing creative thinking and the attitude towards using computers in learning Biology to second grade in secondary schools in Riyadh. Journal of Sanaa University for Educational and Psychological Science, 7(1), 112-139.

Shiratuddin, N., Landoni, M., Gibb, F., \& Hassan, S. (2003). E-book Technology and Its Potential Applications in Distance Education. Texas Digital Library, 3(4).

Shubair, E. (2011). The Effect of Problem -Solving Strategy on the Treatment of Mathematics Learning Difficulties for Eighth Graders (Unpublished Master's Thesis). AL Azhar University, Palestine-Gaza.

Stubbé, H., Badri, A., Telford, R., Hulst, A., \& Joolingen, W. (2016). E-Learning Sudan, Formal Learning for Out-of-School Children. Electronic Journal of e-Learning, 14(2), 136-149.

Sufiani, M. (2008). The importance and use of e-learning in teaching Mathematics at the secondary level from the viewpoint of the parameters and Supervisors (Unpublished Master's Thesis). Umm Al Qura University, KSA.

Ulstad, S. O., Halvari, H., Sørebø, Ø., \& Deci, E. L. (2016). Motivation, Learning Strategies, and Performance in Physical Education at Secondary School. Advances in Physical Education, 6, 27-41.

Vibulpho, J. (2016). Students' Motivation and Learning and Teachers' Motivational Strategies in English Classrooms in Thailand. English Language Teaching, 9(4), 64-75.

\section{Copyrights}

Copyright for this article is retained by the author(s), with first publication rights granted to the journal.

This is an open-access article distributed under the terms and conditions of the Creative Commons Attribution license (http://creativecommons.org/licenses/by/4.0/). 